\title{
20
}

\section{DENSIFICATION AS THE KEY TO SUBURB REGENERATION}

\section{The Case of Driescher Hof in Aachen}

\author{
Giuseppe Verterame
}

The Driescher Hof district in Aachen, chosen as the design experimentation context at

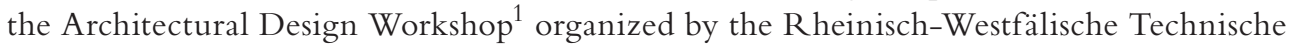
Hochschule of Aachen as part of the ArchéA project, represents an emblematic case of the extreme suburbs of many European cities for its settlement characteristics, urban phenomena, and critical issues related to the absence of public space.

These parts of the city are often the result of plans linked to satisfying certain urban planning standards, which have unreasonably artificialized the natural areas of the territory into a set of diffuse fragments for decades. The suburbs are most distinguished by their extension and discontinuity. These phenomena have generated a dispersion of the urban form, bringing with it the effects of land consumption, the absence of collective space of a certain quality, lack of services, and problems related to architectural and urban recognition. This leads to an image of the city that spreads without any rules, producing urban appendages that are unrelated, inhomogeneous, discontinuous, and lacking a relationship with the preexisting buildings in which the characteristics of a certain urbanity are clearly outlined. The intervention on these parts becomes an important opportunity to rethink the city with a view to urban regeneration, with the aim of systematizing its spatial resources and enhancing the places, seeking a renewed urban sense. Today, the suburbs represent the largest part of the territory as a result of a 'suburban' urban production that has canceled the sense of the center, as a place where dynamic forces connected to each other that animate the city coexist.

The suburbs still contain a lot of material to be reused; these are often spaces enclosed between buildings, lacking in quality and transformed into residual spaces in search of new identities.

The architecture of the city is currently undergoing a redefinition of its operational tools capable of carrying out "an overall restructuring that obviously, while safeguarding the built heritage, captures its evolutionary potential, the possibility of becoming another city as a whole, willing to become the privileged field of design interpretation" (Quintelli 2011, 142).

In the specific case of the heterogeneous district of Driescher Hof, this is also found in an incomplete urban condition, evident from its overall design created in separate parts 
and often based on logics of speculative use of the urban space. With a mainly residential function, this portion of the district is in the southeast end of the city; its southern edge is an intense unspoiled natural environment that becomes rural in the urban vicinity; to the east is the infrastructural element of Autobahn 44, a federal highway that connects numerous cities in Germany and Belgium; to the north with part of the long straight Triererstraße that connects it to the urban center and to the west with buildings belonging to the Forst district, an administrative area that also includes the area of Driescher Hof.

More specifically, in the immediate vicinity of the project site identified, then questioned within the analysis that involved the whole district, there are parts that, overall, fail to establish a spontaneous urban effect: a strong discontinuity is noted among its components, the absence of a systematic nature capable of characterizing this part of the city with a meaning that can be traced back to an experience of space that is simultaneously unitary and addressed to the community. In fact, from the observation and analysis carried out it is possible to identify - from west to east - some architectural and spatial individualities, such as the disused space of the Theodor-Körner barracks on Lintertstraße, the Thomas Torkler manufacturing complex and its (occasional) extraction site, and a heterogeneous fabric with variable densities composed of different building types - tower, in-line buildings, and terraced houses. A conspicuous green area is inserted in the central zone without producing particular benefits from the aesthetic landscape and use perspective; it is a deconstructed element in relation to the built elements, inaccessible from the residential area due to a strong difference in height.

The observation of urban phenomena useful for the design activity follows a transcalar process, which depending on the objectives widens and narrows the analytical field from the particular to the general and vice versa, in search of the bases on which to reestablish the construction of a part of the city. The design process uses three different levels of analysis the scale of the territory, the scale of the city, the scale of the district - according to the methodology developed by "Spinner Research 2013 - Designing the built. New integrated quality models for the compact city,"2 later perfected in the Urban regeneration technique through the structured densification of the system of centralities (TDSC). ${ }^{3}$

An analysis was produced at the territorial scale that highlights the particular geographical condition of Aachen, part of a trilateral system - together with Maastricht and Liège - and for this reason interposed and bordering on three nation-states, Germany, Belgium, and the Netherlands. At the same time, it manages to enter into a relationship with two important territorial systems: Düsseldorf-Köln-Bonn-Koblenz, cities all crossed by the Rhine, and the one formed by the cities Essen and Dortmund in the Ruhr Valley. The result is an important strategic potential on a large scale, such as to distinguish Aachen, within an infrastructural apparatus, as a link and a frontier city (Figure 20.1).

The TDSC technique applied defines, first and foremost, the general context for its application: the shaped city, a place "where a physical, formal, spatial and functional continuity remains between the parts that compose it" (Strina 2015, 375). This entity is specified through an empirical procedure that circumscribes the urbanized core of the city, isolating itself in the points where the built is separated into localized points, dispersed in the countryside. It is built by means of a module and its submultiples, the centurial pixel, derived from the dimensional unit typical of Emilia-Romagna settlements.

Territorial signs and areas were then identified, two elements that highlight the composition of the city by parts, where the multiple nature of the city emerges as "the sum of many 


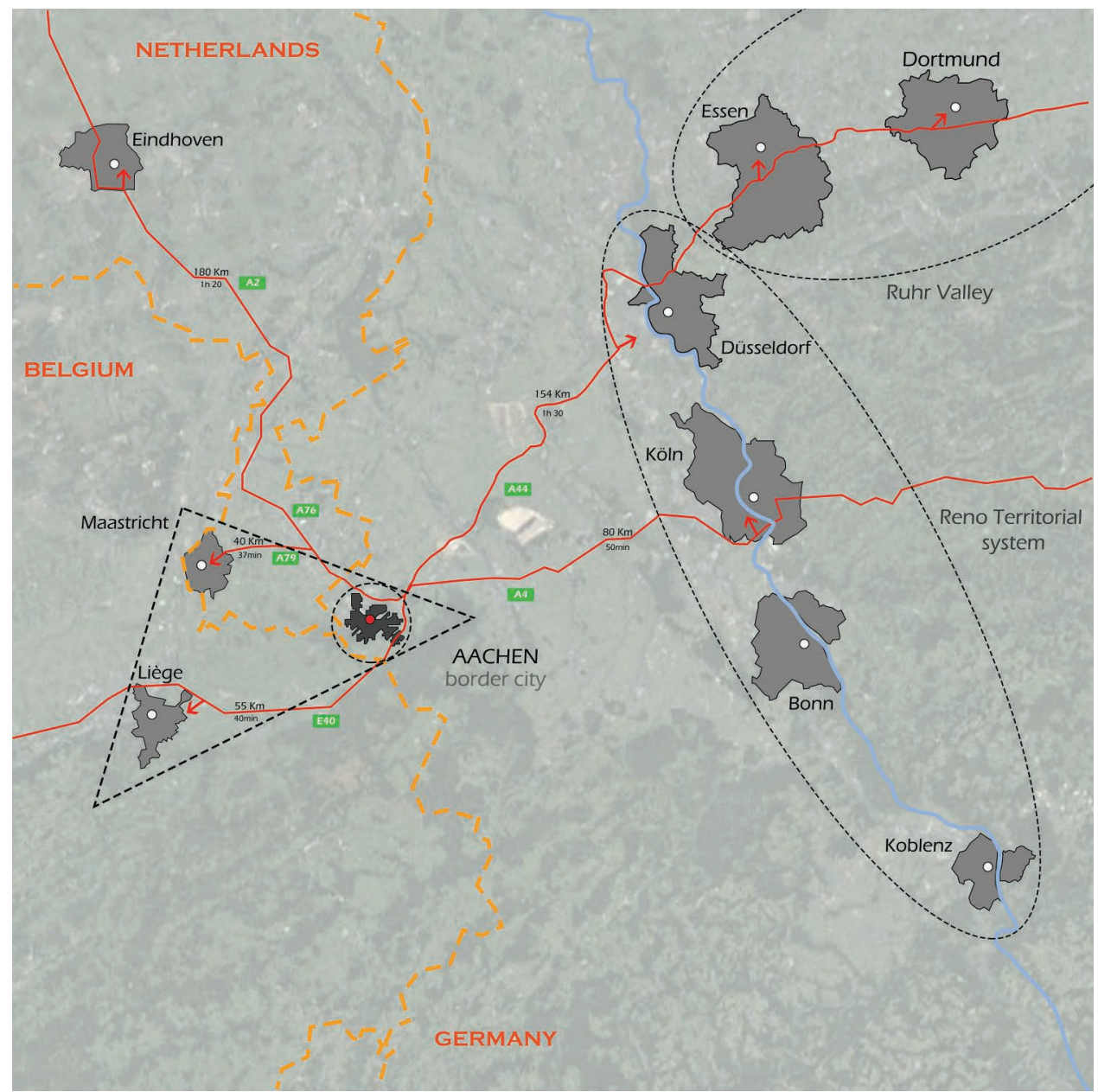

FIGURE 20.1 Territorial scale analysis. Size 90 x $90 \mathrm{~cm}$, scale 1:200,000.

parts, neighborhoods and districts that are very different and differentiated in their formal and sociological characteristics" (Rossi 1966, 42).

The procedure highlighted the ring of the historic center, the 19th-century ring, the railway, the wooded area to the south, the ring road and the highway sections of Autobahns 4 and 44 as territorial signs, and the autobahns respectively connecting to the urban expansions to the north and east, the latter within the urban part considered in the design experimentation.

The territorial signs delimit different areas in order to obtain proof of the heterogeneity of the urban organism, differentiated in its growth processes and in which "particular distinctive characteristics derived from geographical, territorial, morphological and functional factors" (Rossi 1966, 44) can be recognized. The areas of the historic center and the various historical expansions of the city have been identified within the city, from the first suburbs to the more recent ones, some of which can be identified as satellites, which give it a 'sprawling' urban shape (Figure 20.2). 


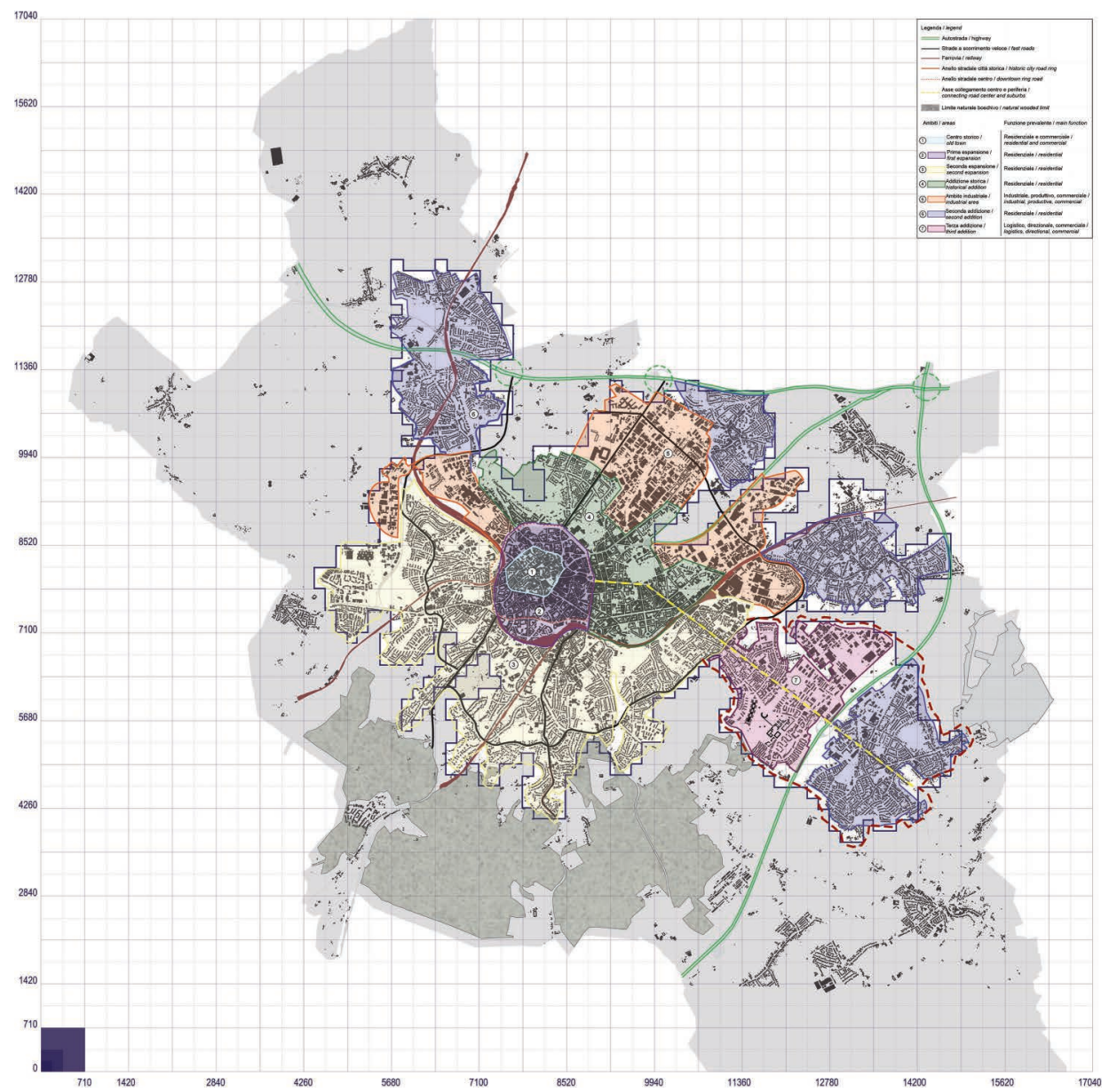

FIGURE 20.2 Identification of a shaped city, territorial signs and areas. Size 90 x $90 \mathrm{~cm}$, scale 1:20,000.

The project area is included within one of these aggregates, located to the southeast and distinguished by its significant size and evident formal autonomy. This citadel is the union of the urban districts Forst and Brand, separated by Autobahn 44, which played a fundamental role in its development, just as the straight road Triererstraße was important for its genesis. In fact, the Napoleonic axis already built in the early 19th century favored a first settlement in the mid-19th century, which then grew until the end of the 1990s. The current road junction of Autobahn A44 - built in the mid-1960s - was already an important suburban connection point in the early decades of the 20th century, as it belonged to the traffic ring of the time. This fact allowed a consistent development of the Brand district, starting after the war and for about 50 years, consolidating and stratifying the defined organic form that we see today.

The mid-period of the 1930s was very important for the definition of that character, which still remains in this part of the city today. In fact, two of the three Aachen barracks 4 were built in the district between 1937 and1939 as part of the remilitarization of the Rhineland. 
This part of the city already appeared strategic and easy to connect with the rest of the territory at that time, so much so that the third barracks of the city were built a few kilometers southwest of the district (Curdes, 1999).

This port and logistical character is a fact that has accompanied the entire district's development, starting from the construction, in a strategic key, of the military complexes up to the most recent construction - nearing completion - of an important grouping dedicated to the tertiary sector and which includes large-scale retail trade - mostly automotive - and a pharmaceutical district. This persistence in the area's spatial-architectural concept has also determined a planning aptitude, in search of the construction of a metropolitan centrality ${ }^{5}$ through the densification of the built in those spaces without an urban role and identity, to favor a polycentric dimension at the territory and city scale. The directional character as well as the

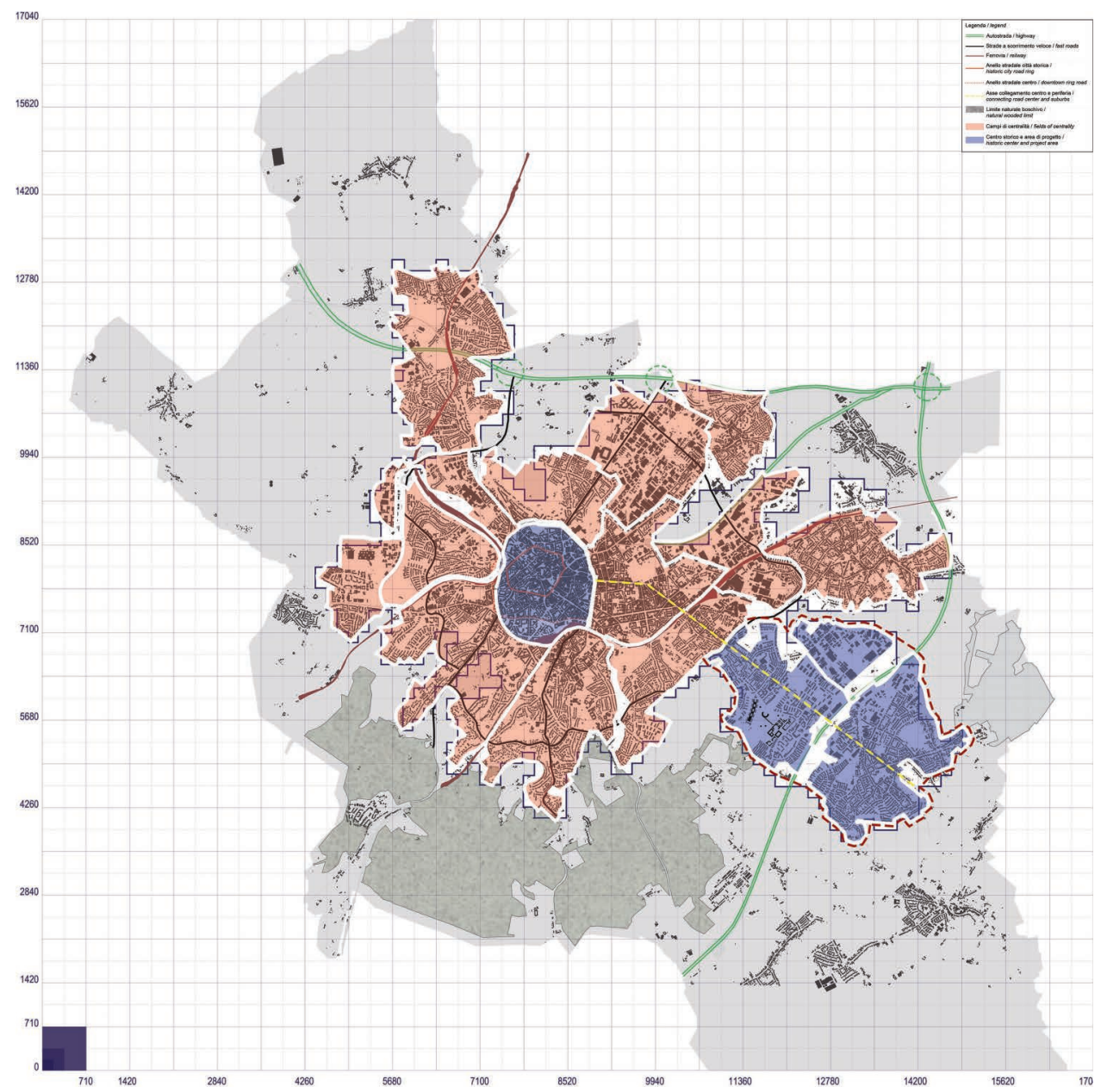

FIGURE 20.3 Distinction of the centrality fields of the city and furthering of the centrality fields of thehistoriccenterand the districtsubjecttointervention. Size $90 \times 90 \mathrm{~cm}$, scale 1:20,000. 
settlement of the intervention depend above all on the presence of the highway exit and on the long-distance relationships in particular toward the polycentric Rhine system.

Within the TDSC technique, the characterization of the different parts of the city is furthered during the analysis of the centrality fields, further partitions with respect to the areas, able to determine urban facts identifiable and definable by morphological autonomy and in which to specify the system of centrality factors. During the workshop, the centrality of the historic center and the one that includes the project area were identified at a demonstration level. In particular, within the latter, research was carried out on factors of centrality, buildings and public spaces in operation or disuse, capable of determining an "[...] even more guaranteed centrality effect if the factors that contribute to determining it find synergistic relationships of proximity among themselves" (Strina 2015, 376; Figure 20.3).

These synergies are synthesized in systems called clusters, which in turn can be configured in higher organisms, polyclusters. These entities spontaneously exchange, according to

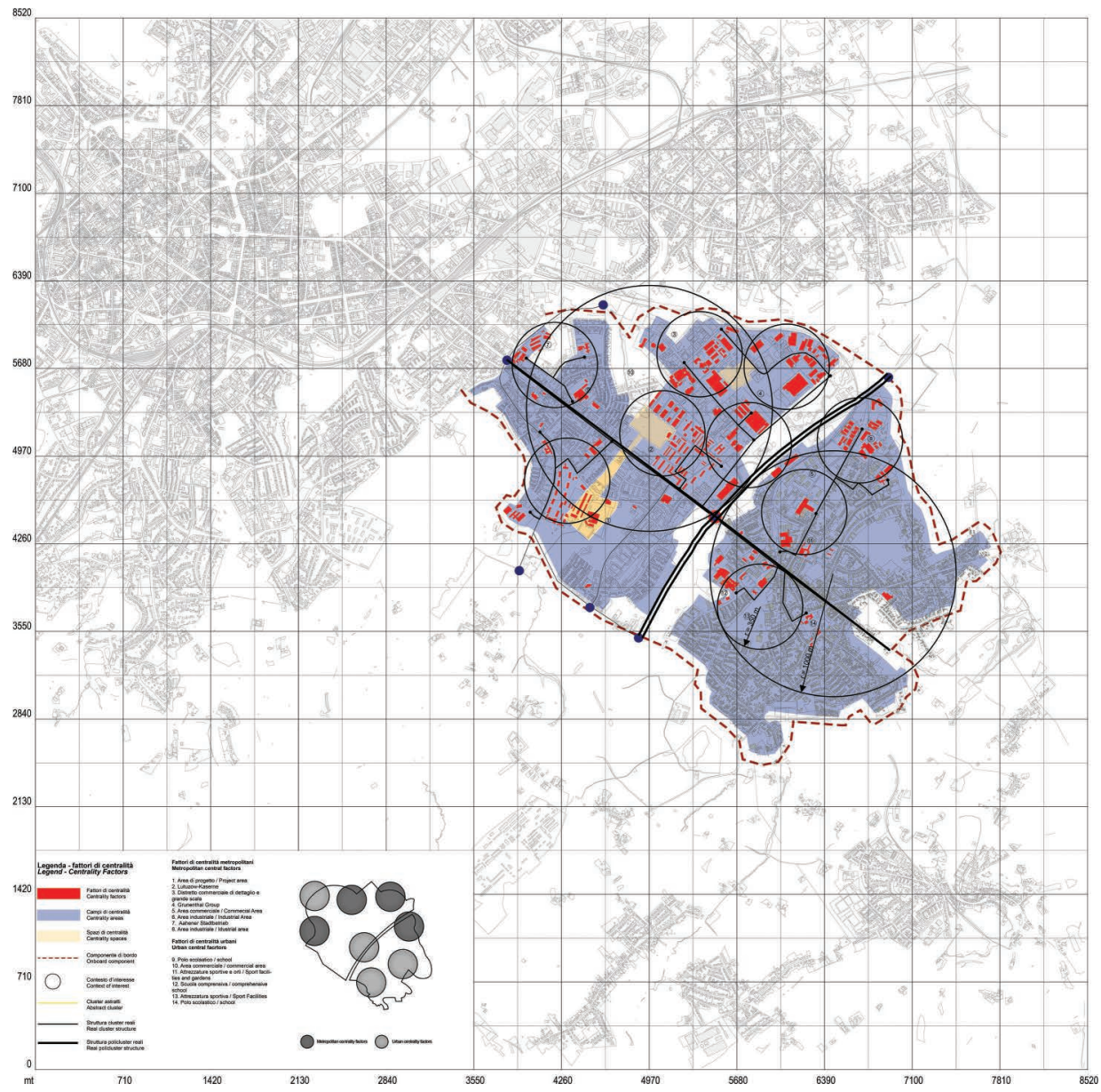

FIGURE 20.4 Analysis and study of centrality factors and centrality space. Size 90 x $90 \mathrm{~cm}$, scale 1:10,000. 
dynamic relational behaviors in which "their relationships cannot be explained by a simple dependence function" (Rossi 1966, 71).

The complex manifestation of the urban structure defined by the study on centrality fields and centrality factors leads to the identification of the centrality space, an area that will be transformed by the new urban centrality project and able to satisfy specific criteria such as accessibility, usability, and visibility (Figure 20.4).

The founding characteristic of this part of the city, described previously, has motivated the design strategy of metropolitan centrality as an architectural device with a strategic position in the reorganization of relations between cities and settlements scattered throughout the territory, also thanks to its representative function on the suburban scale.

To respond to this original character and represent centrality, the architectural paradigm of the Pfalzkapelle has been assumed as the result of a typological montage and as an identity of a specific place or city. The architectural examples chosen for the montage - a high school in Parma designed by Costantino Dardi in 1985, the Fiera-Catena area in Mantua designed by Aldo Rossi in 1982, and the competition project for Regione Friuli Venezia Giulia Headquarter designed by Guido Canella in 1974 composed with the Pfalzkapelle in Aachen - are studied, broken down into the archetypes of the central space and executive space able to connect the parts of the system; "These are two basic principles in the organization of physical space, which recur in a recurrent manner" (Marti Aris 1990, 54) and reused here to respond to the critical issues of the Driescher Hof area described above (Figure 20.5).

Even the compositional matrices of the historic center of the Roman and Carolingian periods are reused and adapted to structure the built components and the open spaces of the project.

The result is an urban composition where residential and executive functions are put in relation with the great availability of natural space, designed to be home to green parterres, including some pavilions, which are gradually inhabited by a greater number of man-made forests closer and closer to the preexisting woodlands to the district's south. The central space is occupied by an octagonal volume with a central courtyard, also octagonal, intended for executive functions. Its northern facade is proclaimed by a long axis that connects with

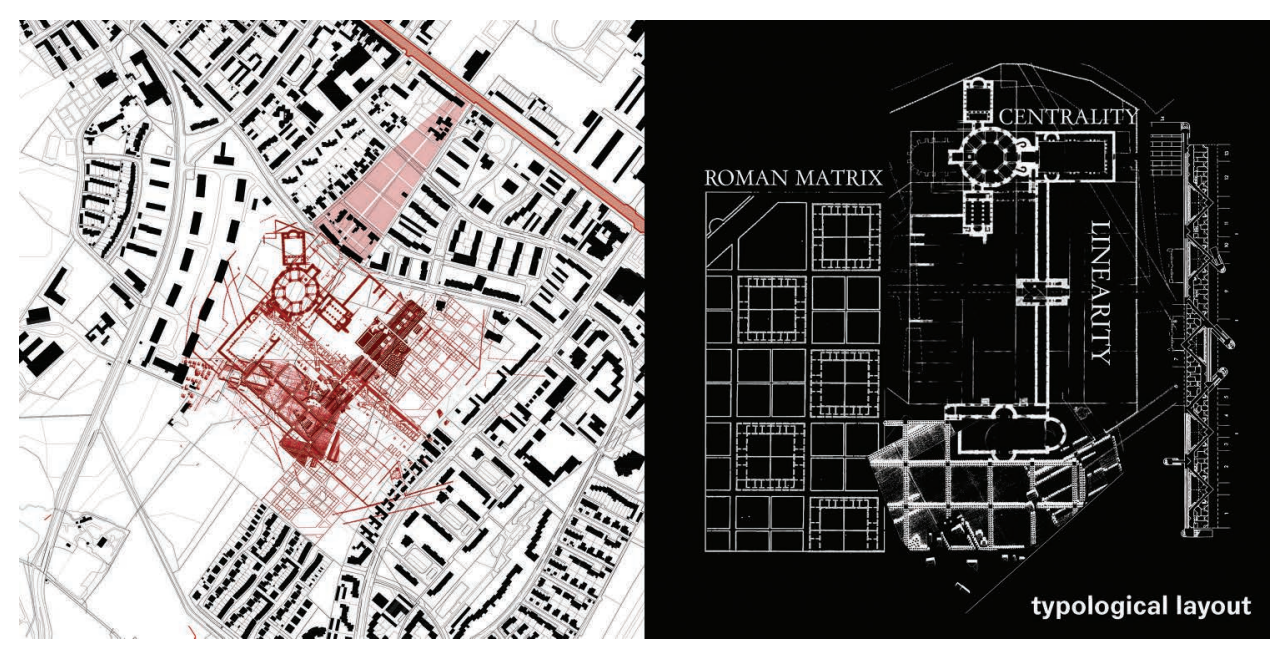

FIGURE 20.5 Typological montage. Architecture examples and archetypes are used as a tool to obtain the identity of a specific place or city. 
Triererstraße and then proceeds to connect with the commercial-productive settlement to the district's north. This linearity in the stretch between the octagonal building and Triererstraße includes a porticoed building that contains commercial functions and anticipates the civil character of the new settlement. This axial intervention is made possible by the removal of a part of the fabric transferred to the east part. Here, the new settlement is built by means of collective residence buildings and based on courtyard and semi-courtyard systems that seek to relate to the preexisting complex. This point is connected by means of a long runner that crosses the entire area. There are points along its path at which to stop or vertical connections with the public park below, or it is possible to reach the central office building and the space in front; further ahead toward the west the research center created in the disused premises of the Theodor-Körner-Kaserne and the courtyard can be reached, occupied by a volume illuminated from above through a system of shed skylights.

The open space at the bottom of the composition takes on a structural value to connect the various free elements (Figure 20.6).

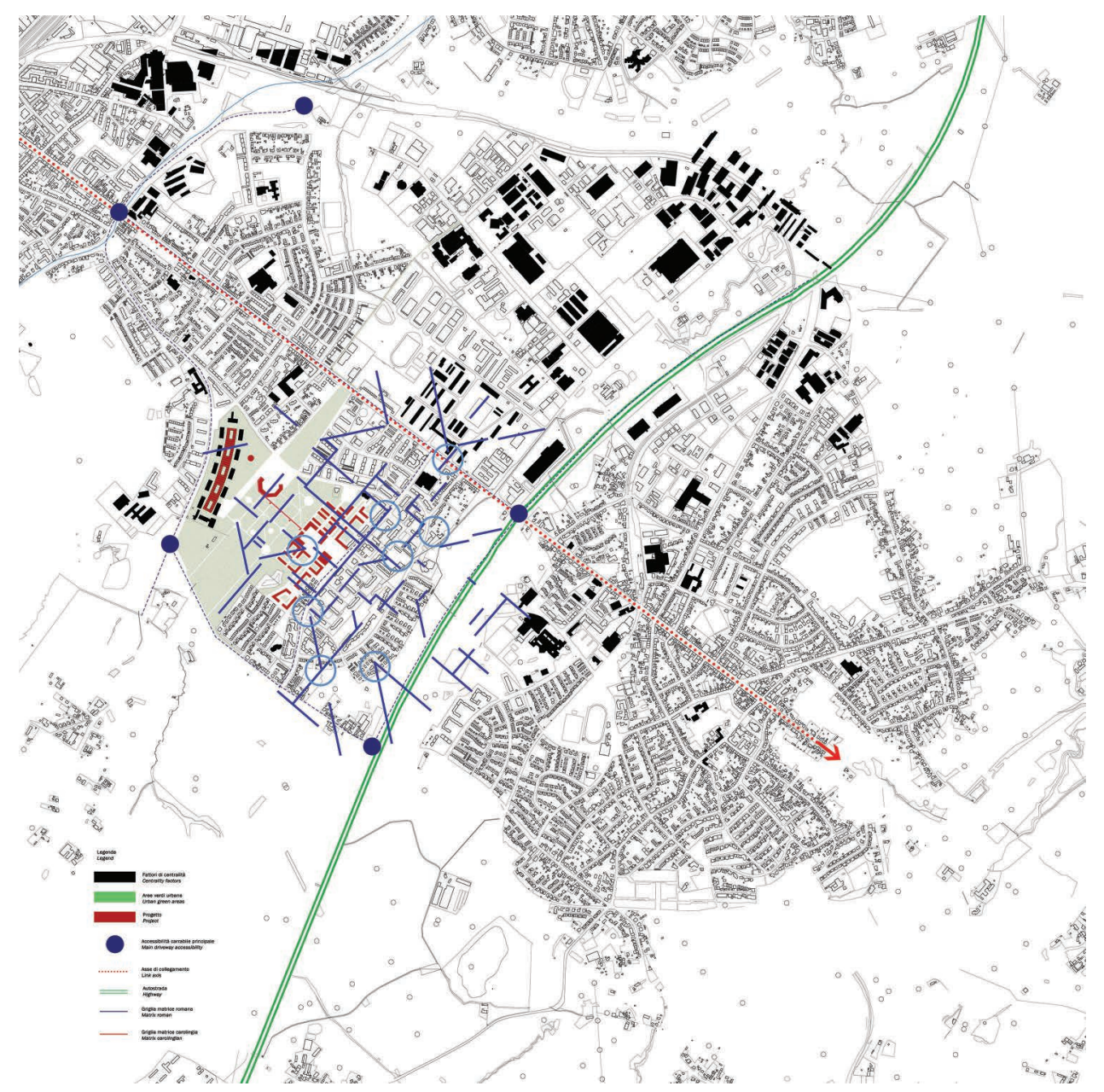

FIGURE 20.6 Meta-design indications. Size 90 x $90 \mathrm{~cm}$, scale 1:5,000. 
The final product is derived from an architecture that is the result of a composition of types - as the Pfalzkapelle - and which consequently obtains a tripartite system that applies an assembly of types of central and linear spaces. This architecture expresses the idea of centrality and is characterized "by being simultaneously unitary and multiple, identifying but heterogeneous, introverted and extroverted, transcalar and, in short, architectural and urban” (Quintelli 2014, 12).

Such a result applied a consolidated methodology and superimposed different levels of in-depth analyses, obtaining an architectural device that is a simultaneous expression of the permanence of an urban fact - obtained by applying the TDSC technique - and of a precise idea of architecture - the manifestation of a type - which accompanied the project "along the entire path of its creative process" (Argan 1965, 78; Figure 20.7).

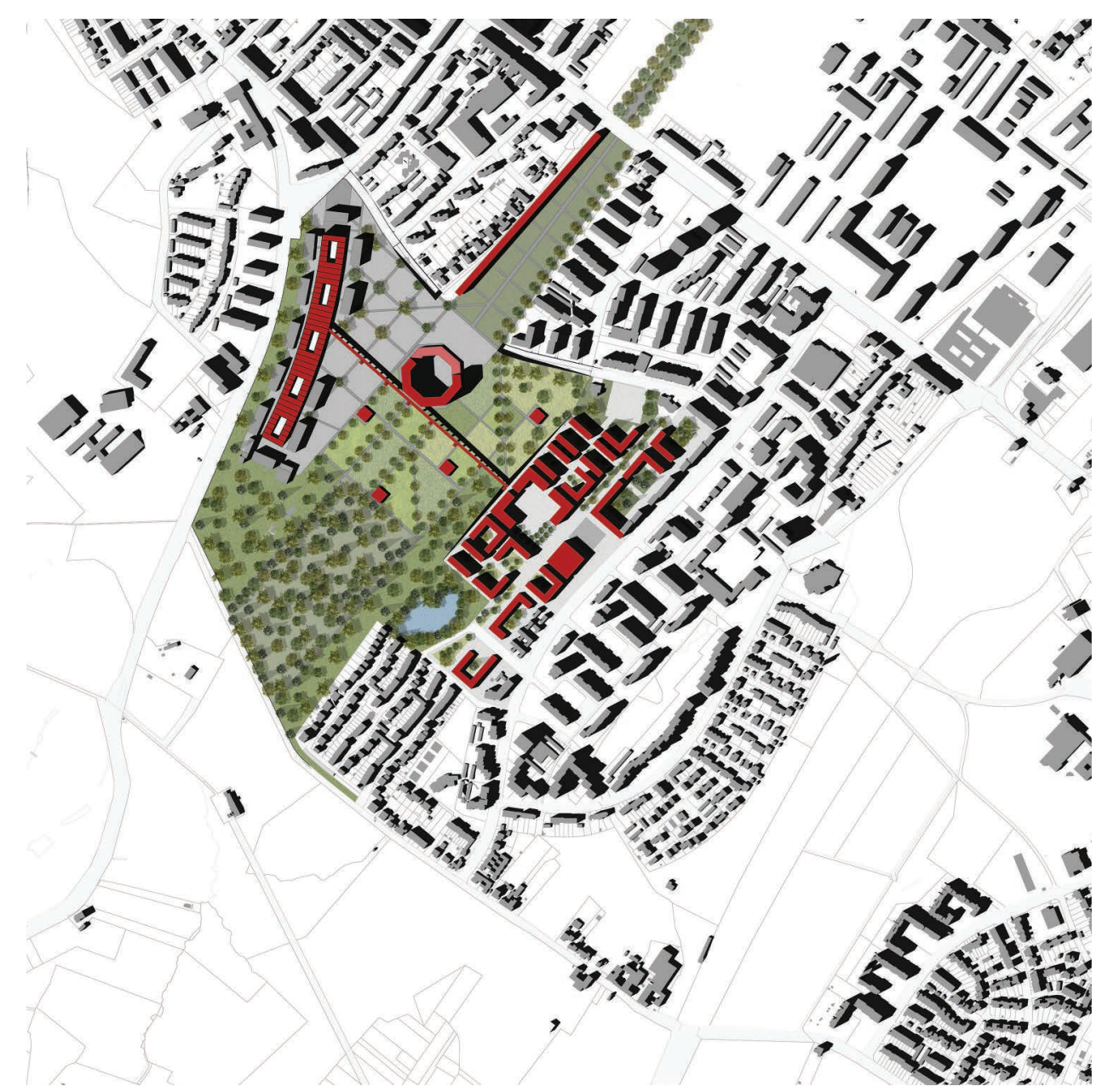

FIGURE 20.7 Volumetric plan. Size 90 x $90 \mathrm{~cm}$, scale 1:2,000. 
Redesigning Driescher Hof area in Aachen - credits

TEACHERS: Carlo Quintelli (supervisor), Enrico Prandi, Carlo Gandolfi

ASSISTANT TEACHERS: Paolo Strina, Giuseppe Verterame, Riccardo Rapparini

STUDENTS: Andrea Bosio, Isabel Chiesa, Irene Di Santo, Ernesto Mario Frigerio, Martina

Ollari, Filippo Piloni, Victor Solonaru, Giorgia Tomasello.

\section{Notes}

1 The workshop was held online from November 21 to November 30, 2020.

2 Funded by the Emilia-Romagna Region, the research was carried out as part of a shared project between the PhD students Annapaola Nolli, Nicola Montini, and Paolo Strina, XXVII cycle, University of Parma; project supervised by Carlo Quintelli.

3 For a concise explanation of TDSC, see the essay by Enrico Prandi in this book.

4 Theodor-Körner-Kaserne built in 1937, Löwenstein Kaserne built in 1938, Lützow Kaserne built in 1939.

5 For more information, see Strina P. 2015, Tecnica di densificazione attraverso la strategia delle centralità urbane di tipo metropolitano [Densification technique through the strategy of metropolitan urban centers], University of Parma: Doctoral thesis. The TDSC technique has already been used in the project of the former fruit and vegetable market of Bologna and presented in the chapter by Paolo Strina in this book.

\section{Bibliography}

Amistadi L. and E. Prandi. 2010. European City Architecture. Structure, Project, Image. Parma: FAEdizioni. Argan, G. C. 1965. Sul concetto di tipologia architettonica [On the concept of architectural typology]. In Progetto e destino [Project and Destiny], G. C. Argan Il Saggiatore, Milan, 75-81.

Aymonino, C. 1977. Lo studio dei fenomeni urbani [The study of urban phenomena]. Rome: Officina.

Curdes, G. 1999. Die Entwicklung des Aachener Stadtraumes. Der Einfluß von Leitbildern und Innovationen auf die Form der Stadt. Dortmund: Dortmunder Vertrieb für Bau und Planungsliteratur (accessed December 18, 2020). https://issuu.com/mondragone/docs/aachener_stadtraum

Martí Arís, C. 1990. Le variazioni dell'identità. Il tipo in architettura [The variations of identity. The type in architecture]. Milan: CittàStudi

Quintelli, C. 2011. Designing the built. Architectural strategies for the compact city. In European City Architecture. Structure, Project, Image, Amistadi L. and E. Prandi, 140-145. Parma: FAEdizioni.

Quintelli, C. 2014. Designing centrality, regenerating the suburbs: Sant'Eurosia in Parma. In Compact City Architecture 2, ed. E. Prandi, 8-15. Parma: FAEdizioni.

Rossi, A. 1966. The Architecture of the City. Padua: Marsilio (1986 Cambridge).

Rowe, C. and F. Koetter. 1983. Collage City. Cambridge, MA: MIT Press.

Strina, P. 2015. Tecnica di densificazione attraverso la strategia delle centralità urbane di tipo metropolitano [Densification technique through the strategy of metropolitan urban centers]. University of Parma: Doctoral thesis. 